\title{
Egypt: Family planning providers should encourage clients to discuss sexual problems
}

Frontiers in Reproductive Health

Follow this and additional works at: https://knowledgecommons.popcouncil.org/departments_sbsr-rh

Part of the Health Services Research Commons, and the International Public Health Commons How does access to this work benefit you? Let us know!

\section{Recommended Citation}

"Egypt: Family planning providers should encourage clients to discuss sexual problems," FRONTIERS OR Summary. Washington, DC: Population Council, 2000. 


\section{Egypt Access \& Quality of Care}

OR Summary 7

\section{Family Planning Providers Should Encourage Clients to Discuss Sexual Problems}

\begin{abstract}
Both clients and providers welcomed the inclusion of discussions on sexuality during family planning counseling. Providers who were trained in sexuality counseling were more likely to discuss sexual matters with clients. Clients preferred to have the provider initiate the discussion.
\end{abstract}

\section{Background}

This 1999 study, the first of its kind in Egypt, examined the feasibility and impact of introducing discussions of sexuality during family planning (FP) consultations. Conducted by the Population Council in collaboration with the Egyptian Ministry of Health and Population (MOHP), the study took place in four MOHP clinics and two private clinics affiliated with the MOHP. Nurses and physicians at all six clinics attended a two-day training session on contraceptives with an emphasis on barrier methods.

Providers in the three clinics that had been randomly chosen as intervention sites also received three days of training on sexuality, gender and counseling skills. To assess the acceptability of sexuality counseling as well as impact of training, researchers interviewed 25 providers and 503 clients, held five focus group discussions, and debriefed seven "mystery clients" (women who posed as clients).

\section{Findings}

- Family planning consultations with trained providers were more likely to include a discussion of sexual matters compared with consultations with untrained providers (see Table). More than two-thirds (71\%) of the clients who received sexuality counseling said they were not embarrassed to discuss such private issues. The most common sexual problems raised by clients were loss of sexual desire and pain during intercourse. Reports of mystery clients showed that, despite training, providers' technical competence in managing such problems was somewhat limited.

\section{Client Experiences during Family Planning Consultations}

\begin{tabular}{lcc}
\hline Clients who were: & $\begin{array}{c}\text { Control (\%) } \\
(\mathbf{n}=\mathbf{1 8 3})\end{array}$ & $\begin{array}{c}\text { Intervention (\%) } \\
(\mathbf{n}=\mathbf{3 2 0})\end{array}$ \\
\hline Counseled on sexual relations & 18 & 44 \\
\hline Encouraged to ask questions & 84 & 95 \\
\hline Counseled on chosen method's effect on sexuality & 22 & 41 \\
\hline Given a barrier method & 2 & 9 \\
\hline
\end{tabular}




\section{Client Attitudes and Experiences}

"If the doctor asks us those [sexualityrelated] questions we would tell her about our problems but otherwise I would be embarrassed to tell her."

"I often could not have sex with my husband because of the IUD (bleeding)."

- clients interviewed after clinic visits

- Women attending focus group discussions reported various sexual problems related to family planning. Expressing their reluctance to initiate discussion of sexual problems, they said that they would like the provider to ask some routine questions about their sexual relations and indicate a willingness to discuss sexual topics. As confidentiality is a major concern, they prefer to talk with a provider they know, preferably a woman.

- Clients at the intervention clinics were more likely than those at the control clinics to receive counseling on the male condom and to obtain a barrier method, mainly condoms. The majority of clients using barrier methods planned to use them for a short time before switching to another method.
- Clients at the intervention clinics noticed improvements in the quality of care. They were significantly more likely than clients at the control clinics to report that the provider had encouraged them to ask questions, had provided all the information they were expecting, and had explained how their chosen contraceptive method could affect their sexual relations.

\section{Policy Implications}

- Sexuality issues, including potential effects of contraceptive options, should be incorporated into family planning counseling. Pre-service and in-service training for providers should include instruction on sexuality, sexual problems, and their relation to family planning methods.

- Referrals to teaching or university hospitals should be established.

- Health education messages should encourage the public to ask family planning providers about concerns and questions regarding sexuality.

Abdel-Tawab, Nahla et al., 2000. Integrating Issues of Sexuality into Egyptian Family Planning Counseling. For more information, contact:Population Council, 6A Giza St., P.O. Box 115, Dokki, Cairo, 12211 Egypt. Tel 20-2-571-9252; Fax 202-570-1804; E-mail frontiers@pccairo.org.

This project was conducted with support from the U.S. AGENCY FOR INTERNATIONAL DEVELOPMENT, Office of Population, under Cooperative Agreement Number HRN-A-00-98-00012-00. 